\title{
JUZGANDO CRÍMENES DE LESA HUMANIDAD Avances, retrocesos y qué podemos aprender de la experiencia*
}

\author{
JUDGING CRIMES AGAINST HUMANITY \\ Progress, setbacks and what we can learn from experience
}

\author{
Mariana Catanzaro**, Dolores Neira***, Hernán I. Shapiro****
}

\begin{abstract}
RESUMEN: El artículo expone el contexto de la última dictadura militar en la Argentina, y el posterior camino en el juzgamiento de los crímenes de lesa humanidad que tuvieron lugar en ese período. Se describe cómo se utilizaron las leyes amnistías e indulto en el caso argentino, y se analiza la incompatibilidad de estos mecanismos en el juzgamiento de delitos de lesa humanidad, en virtud de los compromisos y obligaciones internacionales de protección de los derechos humanos de suscriptos por los Estados. Además, se estudia el rol de las víctimas y el concepto de reparación, un elemento primordial en este tipo de procesos y en particular en el derecho penal.
\end{abstract}

ABSTRACT: The article presents the context of the last military dictatorship in Argentina, and the subsequent path in the prosecution of crimes against humanity that took place during that period. It describes how the amnesties and pardon laws were used in the Argentine case, and analyzes the incompatibility of these mechanisms in the prosecution of crimes against humanity, due to the international commitments and obligations to protect the human rights subscribed by the States. In addition, it explores the role of victims and the concept of reparation, a fundamental element in this kind of processes and particularly in criminal law.

PALABRAS CLAVE: Crímenes de lesa humanidad, Estado de derecho, justicia restaurativa, juicios de la verdad, democracia, víctima, obligaciones internacionales, amnistía, reparaciones.

KEYWORDS: Crimes against humanity, rule of law, restorative justice, truth trials, democracy, victim, international duties, amnesty, reparations

Fecha de recepción: 22/03/2021

Fecha de aceptación: 22/03/2021

doi: https://doi.org/10.20318/universitas.2021.6203

\footnotetext{
* El presente manuscrito se realiza en base a la ponencia homónima presentada en el II Congreso de la Asociación de Estudiantes y Ex-Alumnos/as del Instituto de Derechos Humanos Peces Barba [2021].

** Mariana Catanzaro, E-mail: marianacatanzaro@gmail.com, Universidad Nacional de La Plata.

*** Dolores Neira, E-mail: doloresneira@gmail.com, Universidad de Buenos Aires.

${ }^{* * * *}$ Hernán I. Schapiro, E-mail: hernanschapiro@gmail.com, Universidad Nacional de La Plata.
} 


\section{1.- INTRODUCCIÓN}

La pandemia nos ha puesto en la encrucijada de avanzar de alguna manera en el proceso de memoria, verdad y justicia o esperar hasta que las condiciones sanitarias se normalicen para continuar los juicios como se venían desarrollando.

Esta última alternativa era la peor. Implicaba suspender los juicios de lesa humanidad durante el tiempo que durase la pandemia $y$, en el proceso de juzgar a quienes cometieron tales atrocidades, implicaba la chance concreta y real de que más imputados pudieran quedar impunes y más víctimas fallezcan sin la reparación correspondiente.

Si la alternativa es la injusticia absoluta y la impunidad de quienes cometieron crímenes de lesa humanidad, el sentido en que deben ir los operadores del derecho es el contrario.

El caso argentino es uno de los primeros y más exitosos ejemplos de justicia restaurativa vinculado al terrorismo de Estado. Se trata de un modelo que reposa sobre tres pilares fundamentales: memoria, verdad y justicia.

El juicio a las Juntas Militares fue impulsado por un gobierno constitucional en 1985, siendo el puntapié inicial de la asunción de responsabilidad de las fuerzas armadas por los crímenes cometidos contra la población civil.

El Estado asumió el rol de acusador e investigó a sus propios exfuncionarios evitando así que su estructura fuera utilizada para enmascarar las atrocidades cometidas durante la dictadura. Esto se debió, en gran parte, a la demanda incansable de organismos de derechos humanos y de una sociedad que exigía justicia y sanción a los responsables.

Sin embargo, el recorrido que va desde el juicio a los ex comandantes de las juntas militares hasta los primeros procesamientos de agentes de rangos inferiores, tuvo avances y retrocesos, como lo fueron las leyes de Obediencia Debida (1987) y Punto Final (1986) que impusieron límites a la persecución penal en estos casos.

Ciertas medidas adoptadas mediante procedimientos democráticos pueden impedir la investigación, juzgamiento y eventual sanción de los responsables. La idea de que el derecho no es solamente la expresión de la voluntad de las mayorías y que debe garantizar la protección y el respeto de los derechos humanos, es un concepto que se fue forjando en el derecho internacional y consolidado en la etapa posterior al Holocausto, adoptando la forma de compromisos internacionales de protección de los derechos humanos. Las disposiciones de eximición de responsabilidad como amnistías o incluso los indultos pueden entrar en conflicto con las obligaciones internacionales de los Estados de investigar las violaciones a los derechos humanos, que no sólo fueron asumidas en instrumentos internacionales, 
sino que, además, es un deber del Estado para con su ciudadanía y para con las víctimas, debido a su derecho de acceso a la justicia.

Las leyes de Obediencia Debida y Punto Final fueron derogadas mediante la ley 25.779 en el año 2003 lo que implicó un cambio en el paradigma de los juicios por crímenes de lesa humanidad. El sistema de justicia se puso al servicio de las víctimas y sus familiares, quienes pudieron (y aún pueden) participar directamente juzgamiento de sus victimarios. De esta forma, se configura uno de los aspectos centrales de la justicia restaurativa: la reparación.

Actualmente se siguen realizando juicios por crímenes de lesa humanidad en los tribunales de la República, y se enfrentan una serie de desafíos propios de estos procesos y otros de carácter más general.

Durante los últimos años la justicia criminal ha ido abandonando la idea de que el conflicto penal se da exclusivamente entre Estado y acusado en virtud del quebrantamiento de la norma, para darle mayor relevancia al rol de la víctima a lo largo del proceso.

\section{2.- EL CASO ARGENTINO}

\section{1.- La última dictadura militar en la Argentina}

La historia política de la Argentina del siglo XX ha sufrido los avatares de periódicas asonadas militares, sostenidas mediante el apoyo de diversos grupos económicos, las jerarquías eclesiásticas, parte de la clase política y del Poder Judicial. La última toma del poder del Estado por el estamento militar se produjo el 24 de marzo de 1976 y se extendió hasta el 10 de diciembre de 1983, cuando se recuperó la normalidad constitucional.

El caso argentino estuvo inserto en un movimiento cívico-militar, alentado desde los Estado Unidos de América, que abarcó prácticamente a todo el cono sur. Dicho movimiento se autodenominó Plan Cóndor, y se cimentó en la denominada Doctrina para la Seguridad Nacional, impulsada a la vez desde la Escuela de las Américas. En esta institución se formaron funcionarios militares que luego aplicaron en el país los métodos y mecanismos de la guerra sucia, enderezados a lograr la "aniquilación del enemigo", previo sometimiento a la tortura, entre otros tratos inhumanos y degradantes.

En Argentina la dictadura militar aplicó de manera planificada y generalizada tales métodos, mediante la creación de una red de centros clandestinos de detención, torturas, desaparición forzada y eliminación de personas, en los que operaban empleados de diversa jerarquía de las fuerzas de seguridad y armadas del Estado, además de individuos pertenecientes a grupos armados paraestatales.

Esto sucedía en el nivel de la clandestinidad, mientras el Estado continuaba dando cumplimiento a sus funciones básicas en materia de 
seguridad en el plano de la legalidad impuesta por el gobierno de facto o, más bien, en el plano no clandestino. En muchos casos los mismos funcionarios que durante sus horas de trabajo atendían labores reglamentarias, en otros momentos o en forma simultánea revistaba en centros clandestinos de detención o emitían órdenes ilegales.

Esta particularidad del caso argentino tuvo efectos en lo referente a la prueba de cargo durante los juicios por crímenes de lesa humanidad, pues en muchas oportunidades, dado que la burocracia estatal siguió funcionando, se registraron formalmente hechos relativos al accionar clandestino de las fuerzas represivas, como por ejemplo certificados de defunción de personas asesinadas, asientos de nacimiento de niños en cautiverio, inhumaciones de cadáveres de personas víctimas de homicidio inscriptas como NN en los registros de los cementerios, menciones y felicitaciones al personal policial o de las fuerzas armadas por tareas desempeñadas en el marco de la autodenominada "lucha contra la subversión".

Cuando la dictadura, debilitada tras la derrota en la guerra de Malvinas y las múltiples denuncias internacionales acerca de la desaparición de personas que llevaron adelante los familiares de las víctimas y algunos organismos de derechos humanos, se hallaba en sus postrimerías emitió el decreto No 22.924 -el día 22 de marzo de 1983-, denominado de autoamnistía, mediante el cual declaró extinguidas las acciones penales emergentes de los delitos cometidos con "motivación o finalidad terrorista o subversiva", desde el 25 de mayo de 1973 hasta el 17 de junio de 1982, así como respecto de "los hechos de naturaleza penal realizados en ocasión o con motivo del desarrollo de acciones dirigidas a prevenir, conjurar o poner fin a las referidas actividades terroristas o subversivas".

Asimismo, publicó un documento, denominado informe final, mediante el cual pretendió justificar las acciones ilícitas cometidas, aduciendo que la actuación de las fuerzas armadas se debió a un imperativo de las circunstancias que la impulsaron que estarían dispuestas a repetir, relegando el juicio sobre los hechos cometidos "al tribunal de la historia". Fueron éstas las primeras acciones del sector militar tendientes a conseguir la impunidad por los crímenes cometidos.

\section{2.- Primera etapa de juzgamiento}

Tras la asunción del gobierno constitucional el 10 de diciembre de 1983, se sancionó la ley No 23.040 -el 22 de diciembre de 1983-mediante la cual el Congreso Nacional declaró la "nulidad absoluta e insanable" de aquella auto-amnistía. Tiempo después, la Corte Suprema de Justicia confirmó la validez de esa declaración de nulidad, en el fallo "Causa originariamente instruida por el Consejo Supremo de las Fuerzas Armadas 
en cumplimiento del decreto No 158/83 del Poder Ejecutivo Nacional", del año $1986^{1}$.

Tras ello, el Poder Ejecutivo Nacional, a través del decreto No 187/83 de 15 de diciembre de 1983- conformó una comisión compuesta por destacadas personalidades del quehacer literario, científico, periodístico, religioso y de la defensa de los derechos humanos, además de tres diputados nacionales -que se denominó Comisión Nacional sobre la Desaparición de Personas (CoNaDep).

Su misión fue esclarecer los hechos relacionados con la desaparición de personas ocurridos en el país. Para ello, recibió miles de denuncias de las víctimas y de sus familiares, acerca de los secuestros y desapariciones de personas; estableció el destino de muchos desaparecidos; ubicó sitios que funcionaron como centros clandestinos de detención y torturas, desnudando su funcionamiento; revisó registros carcelarios y policiales $y$, finalmente, puso en conocimiento de las autoridades los hechos delictivos cuyo conocimiento se obtuvo en virtud de dichas averiguaciones.

La CONADEP elaboró un informe, denominado Nunca Más, en el que consta el producto de sus investigaciones que sirvieron de base a los juicios posteriores.

De manera prácticamente paralela, el 13 de diciembre de 1983, el presidente de la Nación, en su rol constitucionalmente establecido de Comandante en Jefe de las fuerzas armadas, dictó el decreto No 158/83, disponiendo someter a juicios sumario ante el Consejo Supremo de las Fuerzas Armadas a los integrantes de la Junta Militar que usurpó el Gobierno de la Nación el 24 de marzo de 1976 y a los integrantes de las dos juntas militares subsiguientes. Esta modalidad de juzgamiento de los presuntos responsables de crímenes atroces por sus pares estaba en la práctica destinado al fracaso, como se demostró con posterioridad.

Al mismo tiempo, el Poder Ejecutivo remitió al Congreso Nacional un proyecto de ley para modificar el Código de Justicia Militar, introduciendo la posibilidad de apelación de las resoluciones de los tribunales militares a la justicia común. Además, procuró establecer una presunción de obediencia debida, salvo prueba en contrario, respecto de los hechos cometidos por personal militar de las fuerzas armadas, de seguridad, policial y penitenciario bajo control operacional de las fuerzas armadas, que actuaron en las operaciones emprendidas con el motivo alegado de reprimir al terrorismo, cumpliendo órdenes o directivas que respondieron a planes aprobados y supervisados por los mandos superiores orgánicos de las fuerzas armadas y

\footnotetext{
${ }^{1}$ Corte Suprema de Justicia de la Nación (AR), Fallos 309:1689, Causa originariamente instruida por el Consejo Supremo de las Fuerzas Armadas en cumplimiento del decreto 158/83 del Poder Ejecutivo Nacional, Corte Suprema de Justicia de la Nación, cons. 1 [1986].
} 
por la Junta Militar². Quedaban por fuera del amparo de la obediencia debida aquellos que hubieren cometieron "excesos" a partir de la orden recibida, con lo cual debería probarse fehacientemente la inexistencia de un error en la apreciación de la orden.

Estos dos aspectos del proyecto de reforma del Código de Justicia Militar, sumados a los considerandos del decreto No 158/83, revelan los límites que el gobierno de aquel entonces pretendió imponer al juzgamiento de los responsables de los delitos cometidos desde el Estado o con su aquiescencia: juicios acotados a los comandantes en jefe de las fuerzas y en todo caso a miembros de la superioridad, y autodepuración de las fuerzas armadas.

Sin embargo, el Congreso sancionó la ley No 23.049, con algunas modificaciones al proyecto del Poder Ejecutivo, tendientes a que los juicios fueran realizados finalmente por tribunales conformados por magistrados civiles y que de algún modo se pudieran extender más allá de las cúpulas de las fuerzas armadas.

En efecto, la ley No 23.049 dispuso que las cámaras federales fueran instancia de apelación de los tribunales militares, pero, a la vez, ordenó que los tribunales militares les enviaran informes sobre la marcha de los procesos en curso y que las cámaras federales asumieran el conocimiento de las causas cuando los tribunales militares no lo hicieran. Además, indicó que los jueces podían presumir obediencia debida, pero no estaban obligados a ello y estableció que aquella presunción sólo podía aplicarse a quienes carecieron de capacidad decisoria y que, en todo caso, no podía amparar a quienes hubieran protagonizado crímenes atroces o aberrantes.

Es decir que, el Congreso de algún modo alteró la planificación del proceso de juzgamiento que tenía in mente el Poder Ejecutivo Nacional.

Pues bien, ante la negativa de los jueces militares, los juicios fueron llevados a cabo por un tribunal de civil colegiado con competencia penal -la Cámara Nacional en lo Criminal y Correccional Federal de la Capital Federal-, tal como establecía la ley.

La primera sentencia se conoció el 9 de diciembre de 1985 y fue dictada en el emblemático Juicio a las Juntas o causa No 13/84 (excomandantes), resultando condenados Videla, Massera Agosti, Viola y Lambruschini y absueltos Galtieri, Lami Dozo, Graffigna y Anaya.

El otro gran juicio de esta primera etapa fue el correspondiente a la causa No 44, iniciado con motivo del decreto No 280/84, conocida como

${ }^{2}$ Cabe señalar que los diversos proyectos y decretos emanados del Poder Ejecutivo Nacional portaron, de manera más o menos explícita, la denominada teoría de los dos demonios, que consiste en la equiparación de la violencia política ejercida por las organizaciones armadas en Argentina a partir de los sesenta y setenta, con la implementación de la metodología del terrorismo de Estado. Ello viene a significar, del modo en que se la utiliza, una sutil procura de justificación del accionar violento e ilegal desplegado desde el Estado. 
causa Camps, en la que resultaron condenados, mediante la sentencia dictada el 2 de diciembre de 1986, el jefe policial, Ramón Camps, el subjefe Ovidio Riccheri, el comisario Miguel Etchecolaz, el médico de policía Jorge Bergés y el cabo Norberto Cozzani. Asimismo, fueron absueltos los excomisarios Alberto Rousse y Luis Héctor Vides.

Es interesante advertir que en la causa Camps el juzgamiento se extendió a personas que no ocuparon altas jerarquías en la estructura terrorista estatal.

Estos dos juicios fueron los únicos en que se llegó a dictar sentencia antes de la sanción de las denominadas leyes de punto final y de obediencia debida, que iniciaron un período de impunidad que se extendió hasta principios del presente siglo.

\section{3.- Leyes de impunidad}

El juicio a los ex-comandantes resultó de una trascendencia inédita, potenciando la demanda de justicia que venía sosteniendo el movimiento de derechos humanos y promoviendo el desarrollo de nuevas acciones judiciales en Argentina y posteriormente en el exterior ${ }^{3}$.

En efecto, el punto treinta de la sentencia de la causa de los excomandantes ordenó que se pusiera en conocimiento del Consejo Supremo de las Fuerzas Armadas el contenido de esa causa, a los efectos del enjuiciamiento de los oficiales superiores y de todos aquellos que hubieran tenido responsabilidad operativa en las acciones.

La actividad jurisdiccional impulsada por las sentencias en las causas de los ex comandante y Camps y el reclamo incesante de justicia de los familiares, las víctimas y los organismo de derechos humanos, no sólo contrarió el proyecto de juzgamiento acotado que, como vimos, enarbolaba el gobierno nacional, sino que también parecía no aceptar los límites que se pretendían imponer a la extensión de la persecución penal mediante la particular interpretación de la obediencia debida emergente del proyecto de reforma del Código de Justicia Militar y de la ley No 23.049.

Por otra parte, el avance en las investigaciones resultó en la movilización de la corporación militar, decidida por ponerle coto.

Ante ello, el Poder Ejecutivo envió al Congreso el proyecto de la denominada Ley de Punto Final, que en realidad consistía en la caducidad o extinción de las acciones penales derivadas de los crímenes de Estado. En el

3 En la sentencia se tuvo por acreditada la existencia de un plan delictivo sistemático comandado y ordenado por las juntas militares, que incluía el secuestro, la privación de la libertad en condiciones infrahumanas, la tortura, el asesinato, la discrecionalidad en la destrucción de las pruebas de esos delitos y de los cuerpos de las víctimas, y que incluso se promovía atentados contra la propiedad privada como el robo. 
mensaje que acompañó al proyecto se alegaba que la pretensión de la futura ley era la de poner fin al retraso que afectaba a las causas.

La Ley de Punto Final -No 23.482-, dictada el 23 de diciembre de 1986, estableció un plazo máximo de sesenta días corridos para ejercitar la acción penal, citando a prestar declaración indagatoria a los presuntos responsables. Si ello no sucedía en dicho plazo aquéllas debían considerarse extinguidas.

Los efectos de esta ley no sólo fueron reducidos, sino que potenciaron el alcance de las investigaciones, debido a la gran labor de organismos de derechos humanos y de algunos funcionarios judiciales, que trabajaron a destajo para indagar a los sospechados antes del fenecimiento del plazo de caducidad. Esta tarea se valora aún más, si se tiene en cuenta que el plazo abarcaba el mes de enero, cuando los tribunales de toda la Argentina se encuentran en receso por vacaciones, permaneciendo sólo personal de guardia.

Esta circunstancia, sumada a la negativa de los presuntos responsables a presentarse ante los tribunales civiles y a la creciente movilización militar que eclosionó en una asonada durante la Semana Santa de 1987, derivó en el envío, por parte del Poder Ejecutivo al Parlamento, de un proyecto de ley que se conoció como de Obediencia debida.

La ley No 23.521 -de Obediencia Debida-, sancionada el 4 de junio de 1987 constituyó, en los hechos, una suerte de amnistía selectiva, pues estableció la presunción sin admitir prueba en contrario de que quienes a la fecha de comisión del hecho revistaban como oficiales jefes, oficiales subalternos, suboficiales y personal de tropa de las fuerzas armadas, de seguridad, policiales y penitenciarias, no serían punibles por los delitos por haber obrado en virtud de obediencia debida.

Cabe señalar, por otra parte, que en su artículo 2, la ley exceptuaba de dicha presunción a los supuestos de violación, sustracción y ocultamiento de menores o sustitución de su estado civil y apropiación extorsiva de inmuebles, supuestos denominados «excesos» en el proyecto de reforma del CJM remitido por el Poder Ejecutivo.

Es decir, esta ley retomaba una de las ideas basales del gobierno nacional acerca del juzgamiento de los crímenes contra la humanidad.

Las consecuencias de esta ley fueron, entre otras, que los procesados y los condenados comprendidos en sus disposiciones alcanzaron la impunidad, quedando sólo detenidos algunos de los ex-comandantes en jefe de las fuerzas armadas. Asimismo, al establecer tal presunción jures et de jure, se invadió la esfera de competencia funcional propia de los jueces.

No obstante, entre 1989 y 1990, el nuevo gobierno constitucional firmó siete decretos de indulto para siete condenados y unos 300 procesados, justificando dicha decisión en la necesidad de la "reconciliación nacional". Asimismo, indultó también a los ex-jefes guerrilleros. Los indultos 
fueron seguidos por leyes de reparación económica que muchas de las víctimas se negaron a recibir.

\section{4.- Juicios por la Verdad}

La década de los '90 significó para Argentina una etapa de completa paralización de las investigaciones y juzgamiento de los crímenes cometidos desde el aparato del Estado durante la dictadura militar.

El reclamo colectivo de Justicia fue sostenido casi de manera exclusiva por las Madres y Abuelas de Plaza de Mayo, junto a los históricos organismos de Derechos Humanos.

Puede afirmarse, en términos generales, que la persistencia del reclamo de Justicia, sumada al impacto que produjo en la Argentina el fenómeno de la internacionalización del reconocimiento y defensa de los derechos humanos, el ejercicio del poder jurisdiccional por terceros países, fundado en el principio de justicia universal y las revelaciones hechas por el ex-represor Adolfo Scilingo -posteriormente detenido y condenado en España- , funcionaron como impulsores del surgimiento de los denominados Juicios por la Verdad.

Estos consisten en procesos sui generis, enmarcados en un contexto caracterizado por la imposibilidad legal -y política- de continuar con los procesos penales por crímenes de lesa humanidad, sancionando a los responsables.

El objeto de los Juicios por la Verdad -cuyo rasgo central es el de ser declaradamente no punitivos- consiste en el esclarecimiento de los delitos cometidos por el terrorismo de Estado, la averiguación del destino final de los desparecidos, las circunstancias en las que se produjeron las desapariciones y la individualización de los responsables. El procedimiento consistió en la recepción de testimonios de sobrevivientes y familiares y recolección de documentos y registros públicos -tales como archivos de organismos de inteligencia, libros de registro de las morgues y cementerios-, la inspección de sitios en los que funcionarios centros clandestinos de detención, etc.

Es importante destacar que estos procesos, vistos desde la perspectiva histórico-jurídica, cumplieron un papel de gran importancia, puesto que constituyeron la antesala al reinicio de las causas penales y conformaron un reservorio de prueba que, a la postre, resultó la base de las denuncias y procesos criminales posteriores.

A partir de los primeros años de la década del 2000 comenzó una nueva etapa en el proceso de verdad y justicia, en la que aún nos encontramos, caracterizada por la apertura de antiguas y nuevas causas penales por crímenes de lesa humanidad cometidos durante la última dictadura militar. Para ello, desde la perspectiva jurídica, fue de fundamental 
importancia la declaración de inconstitucional de las leyes de impunidad y de los indultos efectuada por numerosos jueces nacionales y por la Corte Suprema de Justicia de la Nación en los emblemáticos casos Simón, de 14 junio de 2005 y Arancibia Clavel de 24 de agosto de 2004.

\section{3.- EL DEBER ESTATAL DE INVESTIGAR Y EL DERECHO A LA PROTECCIÓN JUDICIAL DE LAS VÍCTIMAS}

\section{1.- Deberes estatales y derechos de las víctimas}

La Corte Interamericana de Derechos Humanos (en adelante "Corte Interamericana" o "CorteIDH"), en el caso Velázquez Rodríguez vs. Honduras ${ }^{4}$ ha dicho que la obligación de investigar graves violaciones a los derechos humanos es una obligación de medios y no de fines, y su jurisprudencia es constante al sostener que "debe emprenderse con seriedad y no como una simple formalidad condenada de antemano a ser infructuosa" 5 .

En este sentido, se ha dicho que esta clase de investigaciones deben tener un sentido y ser asumidas por el Estado como un deber jurídico propio. De esto puede entenderse que los procesos judiciales que se llevan a cabo sobre graves violaciones a los derechos humanos son en sí mismos actos de asunción de responsabilidad, no sobre a los hechos investigados, sino sobre la obligación de investigar y de garantizar la protección judicial, conforme a lo establecido en los artículos 1.1., 2 y 25 de la Convención Americana de Derechos Humanos.

Este deber cobra especial relevancia en el caso argentino y el de otras dictaduras contemporáneas en Latinoamérica. Como hemos referido, durante la década de los '90 el Estado Argentino no solo se encontraba en falta en cuanto a su obligación de investigar, si no que, además desoía los reclamos de las víctimas y sus familiares como las Madres y Abuelas de Plaza de mayo.

En este sentido, en el caso Gelman ${ }^{6}$ la Corte Interamericana ha referido que:

ante la gravedad de los delitos cometidos y la naturaleza de los derechos lesionados, especialmente en vista de que la prohibición de la desaparición forzada de personas

\footnotetext{
${ }^{4}$ Corte Interamericana de Derechos Humanos, Velásquez Rodríguez v Honduras Fondo (1988).

5 ibíd., 37.

${ }^{6}$ Corte Interamericana de Derechos Humanos, Gelman v Uruguay (2011).
} 
y su correlativo deber de investigarla y sancionar a sus responsables han alcanzado desde hace mucho carácter de jus cogens ${ }^{7}$.

En consecuencia, la actuación del Estado no puede limitarse a una simple gestión de intereses particulares dependiente de la iniciativa procesal de la víctima o de sus familiares. ${ }^{8}$ Lo mismo ocurre en materia probatoria: la prueba no puede recaer exclusivamente de la aportación privada, sino que la autoridad pública tienen el deber de buscar efectivamente la verdad ${ }^{9}$. El rol de un Estado debe ser proactivo, imparcial y protagónico en la búsqueda de la verdad.

Por otro lado, son los Estados soberanos los primeros responsables en llevar a cabo esta tarea, y quienes se encuentran en mejores condiciones para realizarla eficientemente. Son los Estados quienes se encuentran más cerca de los hechos y quienes comprenden cabalmente los sucesos históricos y circunstancias que fueron escalando hasta materializarse en tales hechos.

En palabras de la Corte Interamericana:

[I]a satisfacción de la dimensión colectiva del derecho a la verdad exige la determinación procesal de la más completa verdad histórica posible, lo cual incluye la determinación judicial de los patrones de actuación conjunta y de todas las personas que de diversas formas participaron en dichas violaciones y sus correspondientes responsabilidades ${ }^{10}$.

En el cumplimiento de su deber de investigar, los Estados tienen la oportunidad para rectificar su historia, recuperar sus instituciones y perseguir a los culpables.

En relación con este último punto, la experta de la ONU, Diane Orentlicher, ha sido categórica en un principio, al sostener que la acusación ejemplar de esta clase de crímenes era condición para disipar los efectos tóxicos de la impunidad ${ }^{11}$.

Sin embargo, posteriormente la experta adoptó un criterio más moderado y admitió ciertas concesiones en razón de la creciente relevancia que cobra el rol de las víctimas en el último tiempo ${ }^{12}$.

\footnotetext{
7 ibíd., 55.

${ }^{8}$ Velásquez Rodríguez (n 1 ) 37.

9 ibíd.

10 Gelman (n 6) 56.

11 Diane Orentlicher, 'Setting Accounts: The Duty To Prosecute Human Rights Violations of a Prior Regime' [1991] Yale L] 2537.

12 Diane Orentlicher, '"Settling Accounts" Revisited: Reconciling Global Norms with Local Agency' [2007] IJT] 10.
} 


\section{2.- Amnistías}

En lo que respecta a las amnistías, Orentlicher se encontraba tajantemente en contra de esta clase de disposiciones al entender que aquellas eran incompatibles con la obligación de investigar y sancionar ${ }^{13}$.

Tanto las amnistías, como los indultos, los plazos de prescripción demasiado generosos y otros tipos de límites a la persecución penal pueden ser vistos como un respaldo a situaciones de impunidad.

Esta clase de medidas son utilizadas a menudo por los gobiernos vencedores para evitar un alzamiento de aquellas fuerzas vencidas, o incluso son dictadas por gobiernos dictatoriales para asegurar su impunidad en el momento que deban abandonar el poder. No resultaría extraño, además, que sean producto de transiciones negociadas para asegurar un traspaso del poder pacifico y obtener la confianza por parte de las fuerzas salientes. Como en el caso argentino, también son utilizadas bajos pretextos de reconciliación o "paz", cuando en realidad, paz y justicia no son mutuamente excluyentes.

Sin embargo, ¿puede un gobierno hacer concesiones sobre la dimensión colectiva del derecho a la verdad?

Al respecto, podemos hacer una distinción entre el deber de investigar y el deber de sancionar, pero claro que uno no tendría sentido sin el otro.

Llevar a cabo una investigación con el fin de dilucidar los hechos de una dictadura y encontrar a los responsables por crímenes de lesa humanidad, sería en parte cumplir con el deber de investigar. Pero, si a la vez se dicta un indulto que los exima de cumplir una pena significaría aceptar y garantizar su impunidad.

En su trabajo actualizado, Orentlicher da lugar a una discusión más amplia sobre las amnistías $y$, aunque muestra cierto escepticismo, hace referencia a dos cuestiones que no pueden ser ignoradas. Por un lado, recuerda las manifestaciones del Secretario General de la ONU en su informe sobre el establecimiento de un Tribunal Especial para Sierra Leona ${ }^{14}$.

Este Tribunal Especial fue establecido en forma conjunta por el Estado de Sierra Leona y la ONU con el fin de investigar violaciones al derecho internacional humanitario y derecho interno de Sierra Leona, ante la preocupación de la comunidad internacional sobre la situación de impunidad en ese país ${ }^{15}$. Al respecto, el Secretario General refirió que las amnistías eran incompatibles en casos de crímenes internacionales como el genocidio,

\footnotetext{
13 ibíd.

14 ibíd.

${ }^{15}$ Acuerdo entre la Organización de las Naciones Unidas y el Gobierno de Sierra Leona para el Establecimiento de un Tribunal Especial para Sierra Leona (adoptado el 16 de enero de 2002).
} 
los delitos de lesa humanidad y otras graves violaciones al derecho internacional humanitario ${ }^{16}$.

El caso argentino se encuentra dentro de estos supuestos, eliminando la posibilidad de aplicar amnistías a los responsables y ejecutores de los hechos de terrorismo de Estado. Los crímenes de lesa humanidad fueron reconocidos en el preámbulo del Estatuto de Roma de la Corte Penal Internacional como "los crímenes más graves de trascendencia para la comunidad internacional en su conjunto" que "no deben quedar sin castigo", resaltando el deber de "adoptar medidas [para] asegurar que sean efectivamente sometidos a la acción de la justicia"17.

En segundo lugar, Orentlicher resalta el papel de las víctimas que, por ser parte de un grupo minoritario o en situación de especial vulnerabilidad, pueden ser invisibilizadas. Aun cuando las amnistías pudieran eventualmente suponerse favorables para lograr la efectividad de un proceso de justicia transicional, medidas de esta clase no pueden ser dejadas en las manos de mayorías. Deben tener en consideración las voces de las minorías ${ }^{18}$ como mujeres, niños, comunidades indígenas, minorías étnicas. Al respecto, se ha dicho que en estos casos las leyes de amnistía impiden el acceso de las víctimas a la verdad de los hechos y, especialmente, a las reparaciones correspondientes ${ }^{19}$.

Esta postura fue adoptada por la Corte Interamericana en el caso citado Gelman v Uruguay, que tuvo su origen en la desaparición forzada de una pareja y la apropiación de una niña nacida en el marco de la detención ilegítima de su madre. Estos hechos nunca pudieron ser investigados en razón de la Ley de Caducidad de la Pretensión Punitiva del Estado, sancionada el 22 de diciembre de 1986, una ley de amnistía en relación con los delitos cometidos en el periodo del régimen militar que ocupó el gobierno uruguayo entre 1973 y 1985.

El hecho de que una amnistía sea dictada por un gobierno democrático, como fue en el caso argentino y también el de Uruguay, no lo reviste de legitimidad automáticamente, pues es sabido por demás que una decisión adoptada en mayoría no es garantía de protección de derechos, mucho menos frente a las obligaciones adoptadas por los Estados en el ámbito internacional ${ }^{20}$.

16 CSNU, 'Informe del Secretario General para el establecimiento de un Tribunal Especial para Sierra Leona' (2000) UN DOC S/2000/915

17 ACNUDH, Instrumentos del Estado de Derecho para sociedades que han salido de un conflicto: Amnistías (S.09.XIV.1 Naciones Unidas, 2009).

18 Diane Orentlicher, '"Settling Accounts" Revisited: Reconciling Global Norms with Local Agency' [2007] IJT] 10.

19 Gelman (n 6) 67.

20 ibíd., 69. 
En este sentido se ha expedido la Corte Interamericana en el citado caso Gelman, al sostener que "la legitimación democrática de determinados hechos o actos en una sociedad está limitada por las normas y obligaciones internacionales de protección de los derechos humanos" adoptadas en instrumentos internacionales e incluso aquellas que surjan de normas de ius cogens.

La Corte agregó que hay cuestiones que se encuentran por fuera del ámbito de decisión de los gobiernos, democráticos o no, y que

particularmente en casos de graves violaciones a las normas del Derecho Internacional de los Derechos, la protección de los derechos humanos constituye un límite infranqueable a la regla de mayorías, es decir, a la esfera de lo 'susceptible de ser decidido' por parte de las mayorías en instancias democráticas, en las cuales también debe primar un 'control de convencionalidad'21.

Volviendo al caso argentino, las leyes de obediencia debida y punto final, a pesar de haber sido dictadas por el Congreso electo en forma democrática, resultan nulas por limitar la administración de justicia en casos de delitos de lesa humanidad. Esto resulta contrario a las obligaciones internacionales de protección de derechos humanos adoptadas por el Estado Argentino, y se encuentra, por lo tanto, por fuera de lo susceptible de ser decidido.

Si bien se ha entendido que el perdón por parte de "individuos, grupos e incluso gobiernos es un recurso valioso" 22 , lo cierto que en muchos casos la promoción del perdón, en forma de amnistías o indultos, puede poner en peligro la previsibilidad, la fiabilidad y la igualdad de trato que se persigue mediante el imperio de la ley ${ }^{23}$.

\section{4.- REPARACIONES}

\section{1.- Qué se entiende por "reparación"}

En lo sucesivo veremos que el término "reparación" está vinculado a otros dos términos: "simbólica" e "integral". ¿Por qué se habla de reparación simbólica e integral? ¿Qué se pretende alcanzar con las reparaciones cuando se trata de delitos de lesa humanidad?

Diremos primeramente que tradicionalmente el universo jurídico se refiere a reparación como a una compensación por un hecho o actuación lesivos contra una persona o su patrimonio. Se trata, entonces, de una conducta posterior al delito para compensar o dar satisfacción al sujeto perjudicado.

\footnotetext{
21 ibíd.

22 Martha Minow, Forgiveness, Law, and Justice [2015] CLR 1615.

23 ibíd.
} 
Cuando nos referimos a delitos de lesa humanidad la definición antes dada es insuficiente.

En estos casos, la reparación

es simbólica porque pretende una compensación que siempre es un desplazamiento desde el daño real hacia un acto de justicia, pretende representarlo en magnitud cualitativa o cuantitativamente, pero nunca repara el daño real producido sobre la víctima ${ }^{24}$.

La reparación es simbólica porque no es aquello que se ha perdido lo que se repara, sino lo que lo representa. En ese sentido, no puede jamás "cubrir la integralidad de perjuicios sufridos por la víctima", ya que se produce sobre un daño en sí irremediable.

En segundo lugar, la reparación es simbólica porque, como acto reparatorio por parte de la justicia, está expuesto -en su significación subjetiva para la víctima- a la relación absolutamente singular que esta establecerá entre lo que la reparación ofrece y aquello que ha perdido.

La reparación simbólica abre un proceso subjetivo, trabajo de simbolización y creación que en la singularidad de la víctima remodelará el símbolo, le asignará un sentido y lo transformará25.

Al mismo tiempo, la reparación debe ser integral. Es decir que deben implementarse medidas de restitución, satisfacción y -sobre todo- garantías de no repetición. Por supuesto, una indemnización sólo económica se aleja del ideal deseado.

Tratar de que se reconstruya la historia y conocer qué pasó con cada uno de los desaparecidos, cómo, cuándo, dónde, quién y por qué se decidió su destino; la oportunidad de que las víctimas sean oídas y de que se reconstruya la verdadera historia de los hechos con el correspondiente juicio y castigo para los responsables y ejecutores del terrorismo de Estado, entre otras cuestiones, harán a la reparación más que completa: integral.

Los distintos poderes del Estado se han hecho eco de la obligación que les toca a fin de reparar simbólica e integralmente a las víctimas. El Congreso de la Nación argentina y la legislatura de la Provincia de Buenos Aires sancionaron diferentes normas a fin de reparar parcialmente los daños sufridos por acciones del propio Estado durante la dictadura.

Se dictaron las siguientes leyes nacionales: ley No 24.043 de beneficios a personas que hubiesen sido puestas a disposición del Poder Ejecutivo Nacional durante la vigencia del estado de sitio, o siendo civiles hubiesen sufrido detenciones de tribunales militares; ley No 24.321 sobre desaparición forzada de personas; la ley No 24.411 de beneficios en concepto de percepción, para los causahabientes de personas que se

24 Graciela Guilis et al., 'Concepto de reparación simbólica' <http://www.cels.org.ar/common/documentos/concepto_reparacion_simbolica.doc>

$(C E L S)$ consultado el 15 de enero 2021.

25 ibíd. 
encuentren desaparecidas; ley No 25.914 de indemnización para niños y niñas nacidos en cautiverio; ley No 26.564 de reparación patrimonial (ampliaciones de las leyes No 24.043 y 24.411 para alcanzar a más beneficiarios); ley No 25.192 de beneficio destinado a causahabientes de personas que fallecieron entre el 9 y el 12 de junio de 1956, con motivo de la represión del levantamiento cívico militar de esas jornadas o de su disidencia política.

También se dictaron leyes de este tenor en el ámbito de la provincia de Buenos Aires, entre ellas la ley No 13.745 de beneficio para progenitores de personas desaparecidas o asesinadas; la ley No 13.697 que establece la exención impositiva de inmuebles que fueron última vivienda de personas desaparecidas o asesinadas; la ley No 13.807 de beneficio para ex detenidos Plan CONINTES; la ley No 13.808 de beneficio para participantes del "Operativo Cóndor"; la ley No 13.940 que dispuso la exención impositiva de inmuebles de ex detenidos e hijos. Asimismo, la ley No 13.026 y modificatoria No 13.624 de reconocimiento a los efectos jubilatorios de cesanteados; y la ley No 12.545 que otorga un reconocimiento a los efectos jubilatorios de cesanteados del servicio penitenciario y policía provincial junto con la ley No 14.042/2009 que estableció una pensión graciable para ex-detenidos con domicilio en la provincia de Buenos Aires.

\section{2.- Reparación integral, no solo económica}

Estas indemnizaciones desde la faz económica no serían parte de una reparación integral sin otras medidas, por ejemplo, la señalización de diversos Espacios de Memoria en donde funcionaron los centros clandestinos de detención, o la incorporación del Día de la Memoria al calendario laboral argentino. También se destaca la reivindicación pública de las víctimas con colocaciones de placas conmemorativas en honor a sus memorias, calles y plazas con nombres de víctimas y la instrucción que corresponde en todos los niveles educativos acerca de la gravedad de los delitos de lesa humanidad cometidos en la Argentina durante la última dictadura, entre otras medidas.

Efectivamente, la compensación pensada por la administración de justicia en cualquier otro supuesto jurídico no es equiparable a la que debiera mandarse ante delitos de tal envergadura.

Como se ha dicho, una compensación, que

siempre es un desplazamiento desde el daño real hacia un acto de justicia, pretende representarlo en magnitud cualitativa o cuantitativamente, pero en los delitos de lesa humanidad nunca se repara el daño real producido sobre la víctima ${ }^{26}$.

26 ibíd., 24. 


\section{3.- Lineamientos normativos de las reparaciones integrales}

Hay una constante evolución en materia de derechos humanos que se conoce como desarrollo progresivo, como consecuencia del principio propersona y la prohibición de regresividad. Las reparaciones por delitos de lesa humanidad en sí mismas están sujetas al control de convencionalidad y, por añadidura, deben ser integrales y formar parte del orden público internacional, que obliga a los Estados parte del sistema interamericano a aplicar (en materia de reparaciones también) ese estándar elevado.

Así el estado de cosas, queda al poder Judicial un rol más significativo: es el encargado de la reconstrucción de los hechos, persecución de los delitos y sus autores, y de sancionar efectivamente a quienes encuentre culpables.

El derecho al que recurren las partes del proceso no sólo incluye las normas de fondo y procedimentales del derecho interno argentino, sino también el derecho internacional de los tratados de derechos humanos.

En ese sentido, un bastión fundamental para las víctimas es la Resolución No 60/147 de la Organización de las Naciones Unidas, que se refiere a los "Principios y Directrices Básicos sobre el Derecho de las Víctimas de Violaciones Manifiestas de las Normas Internacionales de Derechos Humanos y de Violaciones Graves del Derecho Internacional Humanitario a Interponer Recursos y a Obtener Reparaciones" (en adelante "los Principios y directrices"), del 16 de diciembre del 2005. Este instrumento empodera a las víctimas, permitiéndoles que tengan un rol protagónico en el proceso de búsqueda de justicia. Claramente, esto incluye las reparaciones: las víctimas se encuentran dotadas del derecho a interponer recursos y a obtener reparaciones; es decir, a tener un rol protagónico en la sustanciación de los juicios de lesa humanidad.

Hoy por hoy, los juicios de lesa humanidad tienen la participación del Ministerio Público Fiscal como representante del Estado, acusando a los posibles autores de los delitos, las defensas de los imputados particulares 0 provistas por el Estado, y también quienes se constituyan como querellantes en los juicios, es decir, las víctimas con sus abogados, los organismos de Derechos Humanos, Secretarías de Derechos Humanos provinciales y Nacionales.

El principio 15 de la Resolución No 60/147 de la Asamblea General de la ONU establece la obligación de reparar el daño de manera adecuada del siguiente modo:

Una reparación adecuada, efectiva y rápida tiene por finalidad promover la justicia, remediando las violaciones manifiestas de las normas internacionales de derechos humanos o las violaciones graves del derecho internacional humanitario. La reparación ha de ser proporcional a la gravedad de las violaciones y al daño sufrido. Conforme a su derecho interno y a sus obligaciones jurídicas internacionales, los Estados concederán 
reparación a las víctimas por las acciones u omisiones que puedan atribuirse al Estado y constituyan violaciones manifiestas de las normas internacionales de derechos humanos o violaciones graves del derecho internacional humanitario. Cuando se determine que una persona física o jurídica u otra entidad está obligada a dar reparación a una víctima, la parte responsable deberá conceder reparación a la víctima o indemnizar al Estado si éste hubiera ya dado reparación a la víctima27.

Más adelante, en los principios 23 y 32, señala que la prescripción no se aplicará a los delitos graves conforme el derecho internacional, y que "toda víctima debe tener la posibilidad de ejercer un recurso accesible tanto por la vía penal como por la vía civil, administrativa o disciplinaria".

Estos principios y directrices han quedado plasmados en el Código Civil y Comercial argentino de 2015. En el artículo 2561, se indica que las acciones civiles derivadas de delitos de lesa humanidad son imprescriptibles. Sin embargo, hay jurisprudencia en el marco interno argentino que ha decidido en sentido contrario a la norma.

La cuestión sobre las prescripciones de acciones civiles por delitos de lesa humanidad se debate aún en la Corte Suprema de Justicia de la Nación Argentina (CSJN) sin unidad de criterios. Como precedente podemos mencionar el fallo Larrabeiti Yáñez, dictado en 2007 y la causa Villamil, Amelia Ana c Estado Nacional, de 2017. En esta última, la mayoría de los miembros de la CSJN concluyó que los reclamos formulados por las víctimas de delitos de lesa humanidad no son imprescriptibles y que, por ende, para dar lugar a una sentencia condenatoria por la responsabilidad del Estado, las acciones están sometidas a las disposiciones que establecen el plazo de prescripción dentro del cual deben ser útilmente promovidas ${ }^{28}$.

Finalmente, la importancia de los Principios y Directrices radica principalmente en su abordaje desde la perspectiva de la integralidad, desde al menos, cinco dimensiones diferentes:

(1) la restitución, buscando en medida de lo posible el restablecimiento de la situación previa de la víctima;

(2) la compensación monetaria, en concepto de indemnización;

(3) la rehabilitación, de acuerdo con la atención médica y psicológica que las víctimas o sus cercanos requieran;

(4) medidas de satisfacción, esto es, sanciones efectivas contra los perpetradores y la puesta en conocimiento de la sociedad toda de la verdad de los hechos traídos a juicio. Finalmente,

\footnotetext{
27 AGNU Res 60/147 (21 marzo 2006), UN Doc A/RES/60/147.

${ }^{28}$ 'La Corte Suprema, por mayoría, ratificó su precedente sobre la prescripción de acciones civiles contra el Estado en juicios de lesa humanidad' (CIJ, 28 de marzo 2017) <https://www.cij.gov.ar/nota-25380-La-Corte-Suprema--por-mayor-a--ratific--suprecedente-sobre-la-prescripci-n-de-acciones-civiles-contra-el-Estado-en-juicios-de-lesahumanidad.html> consultado el 16 de enero de 2021.
} 
(5) la prevención, que es el correlato de la garantía de no repetición de las violaciones a los derechos de las víctimas (ni a ninguna persona nunca más).

En el marco de la OEA, la Corte Interamericana Derechos Humanos, en el caso Órdenes Guerra y Otros v Chile ${ }^{29}$, hizo un análisis sistemático, teleológico y evolutivo del derecho a la reparación integral de las víctimas de delitos de lesa humanidad y estableció estándares regionales que se fundan en los desarrollos actuales del derecho internacional de los derechos humanos.

La labor de la Comisión y de la Corte Interamericana es profusa en materia de reparaciones ${ }^{30}$. Sin embargo, los últimos avances han ido de la mano de ponderar, por sobre el viejo mandato de seguridad jurídica, el imperativo de brindar reparación de daños ocasionados. Esto tanto para Chile como para el Consejo de Estado de Colombia ante el plazo de caducidad de acciones, tratándose de delitos de lesa humanidad.

Esperamos que la CSJN argentina se alinee con este criterio de la Corte Interamericana de Derechos Humanos. Como podrá notarse, lejos de haber alcanzado los máximos objetivos en materia de reparaciones, la cuestión se sigue debatiendo con avances y retrocesos.

Finalmente, diremos que los juicios de lesa humanidad en Argentina tienen finitud, pues el transcurrir del tiempo hace que los responsables de la comisión de los delitos, las víctimas $Y$ sus derechohabientes fallezcan. Los procesos se extienden muchísimo en el tiempo y en la práctica importa la imposibilidad fáctica de alcanzar la plena reparación. Quizá la manera más emblemática de reparar a las víctimas es la reivindicación de los sueños y anhelos de la generación diezmada por los crímenes de la última dictadura. Sin embargo, esta afirmación no tiene un correlato jurídico, sino que es el deseo que subyace en las bases de organismos de derechos humanos que levantan las banderas no solo de memoria verdad y justicia, sino igualdad, justicia social, soberanía del estado.

\section{5.- CONCLUSIONES}

Si bien es cierto que nuestro país ha propiciado un juicio sin antecedentes en el mundo, no es menos cierto que la consigna "Memoria, Verdad y Justicia" ha encontrado innumerables resistencias políticas a lo largo de más de cuarenta años. Tanto es así que hemos atravesado leyes de Punto final y Obediencia Debida, amnistías e indultos, juicios por la verdad

29 Corte Interamericana de Derechos Humanos, Órdenes Guerra y Otros v Chile (2018).

30 La Corte IDH en varios casos se refirió a la reparación integral expresa o tácitamente: Corte Interamericana de Derechos Humanos, Ibsen Cárdenas e Ibsen Peña v Bolivia (2010). Corte Interamericana de Derechos Humanos, Barrios Altos v Perú (2001). Corte Interamericana de Derechos Humanos, Herzog y otros v Brasil (2018). 
y, en los últimos quince años, un nuevo impulso en los juicios de lesa humanidad y la derogación de las leyes de impunidad.

Sin relegar sus funciones en la acusación, el Estado ha cedido espacios en pos de una justicia que se adapte mejor a los intereses de las víctimas. En este sentido, hay varios aspectos de los juicios de lesa humanidad que la justicia penal ordinaria puede tomar y adaptar para que este nuevo modelo sea exitoso, entre ellos, el derecho al acceso de la justicia de la víctima, la importancia de su testimonio y la realización de los juicios como medida de reparación.

En ese transcurrir de los juicios, el Estado argentino ha superado las mil condenas por delitos de lesa humanidad y ha dispuesto un gran número de reparaciones. Estas reparaciones serán tan singulares como los delitos cometidos. Deberán ser, entonces reparaciones simbólicas e integrales.

El ordenamiento jurídico argentino está integrado no solo por normas nacionales sino, además, por los tratados internacionales de derechos humanos que, en el marco de la OEA y de Naciones Unidas, imponen al Estado el deber de buscar la verdad y reparar los daños a las víctimas de la manera más integral posible.

A partir de nuevos principios extraídos del derecho internacional, las víctimas de delitos de lesa humanidad tienen un rol activo en cada proceso que los tiene como parte. Que se puedan reconstruir los hechos es un interés de las víctimas, pero también de la sociedad en su conjunto. El derecho a la verdad pretende alcanzar así la altitud necesaria para reparar el daño de la dictadura de estado. Por este motivo el derecho a la verdad no se acaba en su faz individual, la que interesa a las víctimas, sino que alcanza una faz colectiva: es del interés colectivo de la sociedad.

\section{6.- BIBLIOGRAFÍA}

ACNUDH, Instrumentos del Estado de Derecho para sociedades que han salido de un conflicto: Amnistías (S.09.XIV.1 Naciones Unidas, 2009).

AGNU Res 60/147 Principios y Directrices Básicos sobre el Derecho de las Víctimas de Violaciones Manifiestas de las Normas Internacionales de Derechos Humanos y de Violaciones Graves del Derecho Internacional Humanitario a Interponer Recursos y a Obtener Reparaciones, 60 ONU AGRO en 7 (21 de marzo 2006), UN Doc A/RES/60/147.

Alterini J, y Alterini I, Código Civil y Comercial Comentado ( $1^{\circ}$ ed., La Ley 2015).

CSNU, Informe del Secretario General para el establecimiento de un Tribunal Especial para Sierra Leona, S/2000/915 (4 de octubre, 2000).

Corte Interamericana de Derechos Humanos, Barrios Altos $v$ Perú Fondo, reparaciones y costas, 14 de marzo de 2001.

Corte Interamericana de Derechos Humanos, Gelman v Uruguay Fondo y reparaciones, 24 de febrero de 2011. 
Corte Interamericana de Derechos Humanos, Herzog y otros v Brasil Excepciones preliminares Fondo, reparaciones y costas, 15 de marzo de 2018.

Corte Interamericana de Derechos Humanos, Ibsen Cárdenas e Ibsen Peña v Bolivia Fondo, reparaciones y costas, 1 de septiembre de 2010.

Corte Interamericana de Derechos Humanos, Órdenes de guerra y otros v Chile Fondo, reparaciones y costas, 29 de noviembre de 2018.

Corte Interamericana de Derechos Humanos, Velásquez Rodríguez v Honduras Fondo, 29 de julio de 1988.

Corte Suprema de Justicia de la Nación (AR), Fallos 309:1689, Causa originariamente instruida por el Consejo Supremo de las Fuerzas Armadas en cumplimiento del decreto 158/83 del Poder Ejecutivo Nacional [1986].

Corte Suprema de Justicia de la Nación (AR), Larrabeiti Yañez Anatole Alejandro C/ Estado Nacional S/Proceso de Conocimiento [2007].

Corte Suprema de Justicia de la Nación (AR), Villamil, Amelia Ana c/ Estado Nacional s/ daños y perjuicios [2017].

Orentlicher D, 'Setting Accounts: The Duty To Prosecute Human Rights Violations of a Prior Regime' [1991] Yale L] 2537.

Orentlicher D, '"Settling Accounts" Revisited: Reconciling Global Norms with Local Agency' [2007] IJT] 10.

Morales DR, 'Las Obligaciones Por Hechos Del Pasado $Y$ Las Atribuciones De La Cámara De Diputados. Glosas Al Proceso "Patti"', Teoría y crítica del Derecho Constitucional, t. II (2da ed., Abeledo Perrot 2010).

Guilis G et al, 'Concepto De Reparación Simbólica' (Centro de Estudios Legales y Sociales (CELS) 2021) <http://www.cels.org.ar/common/documentos/concepto_reparacion_si mbolica.doc> consultado el 15 de enero de 2021.

'La Corte Suprema, por mayoría, ratificó su precedente sobre la prescripción de acciones civiles contra el Estado en juicios de lesa humanidad' (Centro de Estudios Judiciales (CIJ), 2021) <https://www.cij.gov.ar/nota-25380-La-Corte-Suprema--por-mayora--ratific--su-precedente-sobre-la-prescripci-n-de-acciones-civilescontra-el-Estado-en-juicios-de-lesa-humanidad.html> consultado el 16 de enero de 2021.

Minow M, 'Forgiveness, Law, and Justice' [2015] CLR 1615. 